\title{
Limits to physiological plasticity of the coral Pocillopora verrucosa from the central Red Sea
}

\author{
Maren Ziegler • Cornelia M. Roder • \\ Claudia Büchel · Christian R. Voolstra
}

Received: 12 September 2013/Accepted: 11 July 2014/Published online: 26 July 2014

(C) The Author(s) 2014. This article is published with open access at Springerlink.com

\begin{abstract}
Many coral species display changing distribution patterns across coral reef depths. While changes in the underwater light field and the ability to associate with different photosynthetic symbionts of the genus Symbiodinium explain some of the variation, the limits to physiological plasticity are unknown for most corals. In the central Red Sea, colonies of the branching coral Pocillopora verrucosa are most abundant in shallow high light environments and become less abundant in water depths below $10 \mathrm{~m}$. To further understand what determines this narrow distribution, we conducted a crossdepths transplant experiment looking at physiological plasticity and acclimation in regard to depth. Colonies from 5, 10, and $20 \mathrm{~m}$ were collected, transplanted to all depths, and reinvestigated after 30 and $210 \mathrm{~d}$. All coral colonies transplanted downward from shallow to deep water displayed an increase in photosynthetic light-harvesting pigments, which resulted in higher photosynthetic efficiency. Shallow-water specimens
\end{abstract}

Communicated by Biology Editor Dr. Mark Vermeij

Electronic supplementary material The online version of this article (doi:10.1007/s00338-014-1192-8) contains supplementary material, which is available to authorized users.

\section{Ziegler · C. Büchel}

Department of Biosciences, Institute of Molecular Biosciences, University of Frankfurt, Max-von-Laue-Straße 9,

60438 Frankfurt am Main, Germany

\section{Ziegler}

LOEWE Biodiversity and Climate Research Centre,

Senckenberg Research Institute, Senckenberganlage 25,

60325 Frankfurt am Main, Germany

C. M. Roder · C. R. Voolstra ( $\square)$

Red Sea Research Center, King Abdullah University of Science and Technology, Thuwal, Saudi Arabia

e-mail: christian.voolstra@kaust.edu.sa transplanted to deeper water showed a significant decrease in total protein content after 30 and $210 \mathrm{~d}$ under low light conditions compared to specimens transplanted to shallow and medium depths. Stable isotope data suggest that heterotrophic input of carbon was not increased under low light, and consequently, decreasing protein levels were symptomatic of decreasing photosynthetic rates that could not be compensated for through higher light-harvesting efficiency. Our results provide insights into the physiological plasticity of $P$. verrucosa in changing light regimes and explain the observed depth distribution pattern. Despite its high abundance in shallow reef waters, $P$. verrucosa possesses limited heterotrophic acclimation potential, i.e., the ability to support its mainly photoautotrophic diet through heterotrophic feeding. We conclude that $P$. verrucosa might be a species vulnerable to sudden changes in underwater light fields resulting from processes such as increased turbidity caused by coastal development along the Saudi Arabian Red Sea coast.

Keywords Coral reef - Metabolic plasticity $\cdot$ Red Sea . Pocillopora verrucosa . Transplants

\section{Introduction}

Hermatypic (i.e., reef-forming) corals host intracellular photoautotrophic dinoflagellates of the genus Symbiodini$u m$ as part of an obligate symbiosis. The photosynthetic output of Symbiodinium can cover the entire energy demand of the coral host (Muscatine 1990), explaining why the occurrence of hermatypic corals is limited to the photic zone of warm, oligotrophic oceans (Falkowski et al. 1984). Despite the oligotrophic conditions that are prevalent in tropical coral reefs, the tight nutrient recycling between Symbiodinium and their coral hosts provides the foundation 
of these highly productive ecosystems (Patton et al. 1977; Alamaru et al. 2009). Most coral species have limited distribution patterns along the vertical light gradient, as irradiance in the ocean decreases exponentially with depth. Consequently, a large proportion of hermatypic corals live in the well-lit upper $30 \mathrm{~m}$ of the water column, with only a few specialist species inhabiting the mesophotic zone below $30 \mathrm{~m}$ (Lesser et al. 2009).

In general, Symbiodinium-bearing corals have a high capacity to exhibit physiological plasticity. Physiological plasticity is defined as the mechanism whereby organisms alter their physiology allowing them to acclimate to different environments (e.g., different light regimes; Brown 1997; DeWitt et al. 1998; Gates and Edmunds 1999). In order for corals to maintain high photosynthetic production under distinct light regimes, Symbiodinium cell densities and/or the chlorophyll (chl) content per cell can be modulated (Bongaerts et al. 2011; Cooper et al. 2011a). In addition to increasing chlorophyll concentrations under low light, a larger pool of other light-harvesting (LH) pigments, i.e., chlorophyll $c_{2}$ and peridinin, can be synthesized, which supports efficient light capture and photosynthetic energy conversion (Iglesias-Prieto and Trench 1997). Under increased light levels, the concentration of LH pigments decreases, and a reversed trend of increasing photoprotective (PP) xanthophylls and xanthophyll de-epoxidation in the socalled xanthophyll cycle can be observed. This indicates the activation of photoprotective pathways (Brown et al. 1999). Pulse-amplitude-modulated (PAM) fluorometry facilitates the measurement of photophysiology in situ (Ralph et al. 1999). Its application to various coral species has shown that, with decreasing light, minimum saturating irradiance decreases while maximum quantum yield increases (Frade et al. 2008a; Lesser et al. 2010).

When decreasing light levels exceed the limits of photosynthetic plasticity, autotrophic output decreases (McCloskey and Muscatine 1984) and energy stores may be reduced (Cooper et al. 2011a). However, under lower light levels, some corals can support their mainly autotrophic diet through heterotrophic feeding (Ferrier-Pagès et al. 1998; Palardy et al. 2005; Lesser et al. 2010; Roder et al. 2011). This flexibility between autotrophic and heterotrophic carbon acquisition is one factor that determines a species' ecological niche and distribution range (Anthony and Fabricius 2000; Hoogenboom et al. 2010). Furthermore, under disturbance, more flexible coral species perform superior to species with limited heterotrophic capacity (Grottoli et al. 2006; Roder et al. 2010).

Beyond photoacclimatory processes, the association with different Symbiodinium types is an important variable explaining the depth zonation between coral species (Iglesias-Prieto et al. 2004; Frade et al. 2008b). For instance, a single Symbiodinium type was found to be responsible for the depth distribution of Pocillopora verrucosa in the shallow waters of the Gulf of Mexico (Iglesias-Prieto et al. 2004). Moreover, a change in Symbiodinium type can broaden the ecological niche of a species by conferring a metabolic advantage on their hosts in the respective environment (Bongaerts et al. 2011; Cooper et al. 2011b).

Despite the various physiological mechanisms that allow corals to acclimate to different light regimes, the limits of physiological plasticity (DeWitt et al. 1998; Todd 2008; Auld et al. 2010) are unknown for most corals. In this study, we examined the physiological plasticity of $P$. verrucosa, a major reef-building species of the central Red Sea, along its distribution range (i.e., between 5 and $20 \mathrm{~m}$ ) with a focus on changes in autotrophic and heterotrophic potential. Our aim was to further understand the species' depth zonation and distribution limits by monitoring Symbiodinium and metabolic tissue parameters during a longterm cross-transplantation experiment across the species' distribution depths.

\section{Materials and methods}

\section{Experimental design}

The transplantation experiment was conducted on the oceanfacing side of “Al Fahal” reef (N22 ${ }^{\circ} 15.100$, E038 $\left.{ }^{\circ} 57.382\right)$ approximately $11 \mathrm{~km}$ off the Saudi Arabian central Red Sea coast. At each of the three sampling depths (5, 10, and $20 \mathrm{~m}$ ), five colonies of $P$. verrucosa were collected and split into three equally sized parts (with several branches) in February 2012. Immediately afterward, each triplicate of a given colony was transplanted to one of three experimental depths $(5,10$, and $20 \mathrm{~m})$. One of the experimental depths was the native depth (depth of origin), and two were nonnative transplant depths. Thirty days after the onset of the experiment, in situ photophysiological measurements were taken on each fragment and a sample was taken for subsequent analyses of Symbiodinium densities and pigments. Metabolic parameters (details below) were measured after 30 and $210 \mathrm{~d}$ to examine short- and long-term heterotrophic acclimation, respectively. Further, we sampled on the day of transplantation (d0), and after 30, 90, and $210 \mathrm{~d}$ to examine the Symbiodinium composition and mortality over time.

\section{Environmental sampling}

Physicochemical parameters that potentially influence coral photosynthesis and metabolism were investigated. HOBO Pendant ${ }^{\circledR}$ temperature loggers (Onset, USA) were placed at each of the experimental depths, recording water temperature at 10-min intervals for the duration of the 
experiment $(210 \mathrm{~d})$. At three times around noon during the first $30 \mathrm{~d}$ of the experimental period, CTD (SBE 16plusV2, Seabird Electronics, USA) casts with a mounted photosynthetic active radiation (PAR) sensor $\left(E C O\right.$ PAR $^{\mathrm{TM}}$, WET Labs, USA) were performed. Discrete water samples were taken at 5, 10, and $20 \mathrm{~m}$ using 10-1 Niskin bottles. Water samples were stored on ice in the dark until filtered through GF/F filters (0.7 $\mu \mathrm{m}$, Whatman, UK) using vacuum. Filtrates were analyzed for inorganic nutrient content (phosphate, nitrite, nitrate, and ammonia). The filters were divided in half. One half was lyophilized and weighed on a microbalance (Mettler Toledo, USA) to the nearest $0.01 \mathrm{mg}$ for total suspended matter (TSM) determination; subsequently, this half of the filter was analyzed for stable isotopes (as described below for coral samples). From the other half, pigments were extracted and chlorophyll content was determined according to Jeffrey and Humphrey (1975).

To characterize the reef environments at each depth, four 20-m line intercept transects were conducted. Benthic properties were noted every $50 \mathrm{~cm}$, resulting in 160 data points per depth (English et al. 1997). Along eight replicate $5 \times 1-\mathrm{m}$ belt transects, $P$. verrucosa colony abundance was recorded and the dimensions (width, length, and height) of the first 20 colonies along each transect were measured. The proportion of the hard coral substrate covered by $P$. verrucosa colonies was calculated from mean colony sizes and line intercept transects.

In situ photophysiology

After $30 \mathrm{~d}$, all transplants were analyzed using in situ PAM fluorometry (Ralph et al. 1999). Sampling took place before noon. Three light-adapted quantum yields $\left(\Delta F / F_{m}{ }^{\prime}\right)$ were measured per sample using a Diving PAM (Walz, Germany) followed by a rapid light curve (RLC). During the RLCs, eight increasing light steps (106, 176, 271, 435, 560, 769, 1069 , and $1,558 \mu \mathrm{mol}$ photons $\mathrm{m}^{-2} \mathrm{~s}^{-1}$ ) were applied to the corals for $10 \mathrm{~s}$ each, followed by a saturation pulse. The following RLC parameters were calculated after fitting the model of Platt et al. (1980) using Sigmaplot ${ }^{\circledR}$ software (SPSS, USA): $\mathrm{E}_{\mathrm{k}}$ : minimum saturating irradiance; $\alpha$ : maximum light utilization coefficient (equivalent to initial slope of the RLC), and $\mathrm{rETR}_{\max }$ : maximum relative electron transport rate.

\section{Sample processing}

After in situ measurements, a branch of each transplanted fragment was collected, subsequently rinsed with filtered seawater, and snap-frozen in liquid nitrogen. Coral tissue was removed from the snap-frozen fragments using an airgun and an airbrush with $4{ }^{\circ} \mathrm{C}$ cold $4 \% \mathrm{NaCl}$ solution. After homogenization, aliquots were taken for Symbiodinium cell counts, protein, and stable isotope analyses. The remaining slurry was centrifuged for $5 \mathrm{~min}$ at 3,220g, and the supernatant was removed. The pellet was washed and resuspended twice in $4 \% \mathrm{NaCl}$ solution, and then shockfrozen in liquid nitrogen for HPLC analysis of Symbiodinium pigments. All processing steps were conducted on ice. Coral skeletons were bleached, and their surface area was determined with paraffin wax dipping (Veal et al. 2010).

\section{Symbiodinium densities and pigments}

Symbiodinium densities were determined with six replicate counts in a Neubauer-improved hemocytometer on a light microscope and calculated per coral surface area. The shock-frozen Symbiodinium samples were freeze-dried, and the tubes were closed under $80 \%$ nitrogen $/ 20 \%$ hydrogen atmosphere to prevent oxidation of the reactive alkene double bonds of the pigments (Kowalewska and Szymczak 2001). Dried pellets were suspended using a mortar and pestle, and pigments were extracted in $500 \mu \mathrm{l}$ ice-cold $90 \%$ methanol with $1 \mathrm{mM}$ Tris. After the addition of methanol, cells were disrupted during six 30-s intervals in an ice-cooled ultrasonic bath. Afterward, glass beads (50\% $0.1 \mathrm{~mm}, 50 \% 0.5 \mathrm{~mm}$ ) were added to the solvent, and six intervals of $3 \mathrm{~min}$ in a cooled $\left(-20^{\circ} \mathrm{C}\right)$ bead-beater (TissueLyser LT, Qiagen, Germany) at $50 \mathrm{~Hz}$ were performed. Samples were centrifuged at $2{ }^{\circ} \mathrm{C}$ and $12,846 \mathrm{~g}$ for $10 \mathrm{~min}$ to precipitate proteins. The pellet was inspected visually for complete homogenization, and additional rounds in the bead-beater and ultrasound were conducted if necessary. The supernatant was filtered through a syringe membrane filter $(0.45 \mu \mathrm{m})$, and $20 \mu \mathrm{l}$ of the filtrate was separated on a reverse-phase HPLC column (18C Chromolith, Merck, Germany) using a linear gradient system according to $\mathrm{Pa}$ pagiannakis et al. (2005). All pigments were measured using a Hitachi L-2455 diode array detector (VWR, Germany) and quantified against pigment standards for chlorophyll $a$ and $c_{2}$, ß-carotene, and the xanthophyll cycle pigments diadinoxanthin (ddx) and diatoxanthin (dtx; all DHI, Denmark) according to Papagiannakis et al. (2005). For peridinin (DHI, Denmark), calibration and quantification was carried out in the same way using an extinction coefficient of $132.5 \mathrm{lg}^{-1} \mathrm{~cm}^{-1}$ (Jeffrey and Haxo 1968). Subsequently, the ratio of light-harvesting pigments (i.e., chl $a$, chl $c_{2}$, and peridinin) to photoprotective pigments (i.e., B-carotene, $\mathrm{ddx}$, and $\mathrm{dtx}$ ), and the xanthophyll deepoxidation $\left(\mathrm{dtx}(\mathrm{dtx}+\mathrm{ddx})^{-1}\right)$, was calculated.

Metabolic tissue parameters

Total protein content of tissue slurry was determined after Lowry et al. (1951) against a bovine serum albumin standard (DC protein assay, Bio-Rad, Germany) with a spectrophotometer (SpectraMax Paradigm, Molecular Devices, 
USA). Prior to measurement, the samples were extracted in $0.5 \mathrm{M} \mathrm{NaOH}$ for $30 \mathrm{~min}$ at $90{ }^{\circ} \mathrm{C}$. A tissue aliquot was separated into algal and animal fraction through centrifugation, and the Symbiodinium pellet was washed twice (see above). Both fractions were dried in a centrifugal evaporator. Elemental analyses of carbon and nitrogen concentrations and their isotopic ratios were conducted with an isotope ratio mass spectrometer (Thermo Finnigan MAT, USA). Isotopic ratios are reported as $\%{ }_{0}^{13} \mathrm{C}$ and $\% \delta^{15} \mathrm{~N}$ relative to Pee Dee Belemnite standard and atmospheric nitrogen, respectively.

\section{Symbiodinium community composition}

Symbiodinium cells were separated from the host tissue as detailed above. DNA was extracted using Chelex resin (100-200 mesh, Sigma, USA), and DNA concentrations were determined using Qubit dsDNA HS Assay kit (Invitrogen, USA). About $5 \mu \mathrm{l}$ of extract containing 1.5-3 ng DNA was used for amplification with the forward primer "ITS2intfor" and the reverse primer "ITS2CLAMP" following PCR touchdown protocols detailed in LaJeunesse and Trench (2000) with Qiagen Multiplex PCR kit according to the manufacturer's recommendations. The final volume for all reactions was $25 \mu \mathrm{l}$, and the final concentration of the primers was 0.1 without clamp and $0.3 \mu \mathrm{M}$ for the primer with the GC clamp. PCR products were loaded on an $8 \%$ polyacrylamide denaturing gradient gel (45-80\% urea-formamide gradient) and separated by electrophoresis for $16 \mathrm{~h}$ at $150 \mathrm{~V}$ and $60{ }^{\circ} \mathrm{C}$ (LaJeunesse 2002). Separated bands were stained with SYBR Safe (Invitrogen, USA) for $20 \mathrm{~min}$ in the dark and visualized and photographed on a transilluminator. All prominent bands from the denaturing gel were excised and incubated in $500 \mu \mathrm{l}$ sterile water for $24 \mathrm{~h}$ before re-amplification and sequencing. For re-amplification, the same forward primer was used while the reverse primer did not contain the GC clamp (Coleman et al. 1994). Sequences were submitted to the Bioscience Core Lab at KAUST for sequencing on an ABI 3730xl (Applied Biosystems, USA). Chromatograms of the ITS2 sequences were checked and edited using CodonCodeAligner, aligned with Geneious 5.5.4, and BLASTed against the GeoSymbio database (Franklin et al. 2012) and the GenBank nr database for ITS2 type designations.

In the DGGE profiles, the most prominent band was recorded as indicative of the main Symbiodinium type (LaJeunesse 2002). Furthermore, background types that can lead to complex banding profiles were analyzed through re-amplification of additional bands (LaJeunesse 2002). At each of the four sampling points (i.e., 0, 30, 90, and $210 \mathrm{~d}$ ), we recorded whether a fragment had undergone a change in the Symbiodinium composition. Coral fragments that were deceased or lost were excluded for the respective time point and onwards. The number of fragments that were still alive versus those deceased after $210 \mathrm{~d}$ of transplantation were recorded (excluding all lost fragments). Multiple permutation tests were conducted to test for Symbiodinium composition changes compared to unchanged fragments over all time points. Further, permutation tests were conducted on mortality rate after $210 \mathrm{~d}$ considering the factors "depth of origin" and "transplantation depth." A sequential Bonferroni correction was used to adjust $p$ values.

Data analysis

To test for significant differences after 30-d transplantation, a two-factorial ANOVA was conducted with "depth of origin" and "transplantation depth" as fixed factors. To achieve homogeneity of variance, pmol chl a Symbiodinium cell ${ }^{-1}$, mol peridinin mol chl $a^{-1}, \alpha, \mathrm{E}_{\mathrm{k}}$, and $\delta^{13} \mathrm{C}$ of Symbiodinium were square-root-transformed. All other parameters (detailed above) met the assumptions of normality (Shapiro-Wilk's $W$ test) and homogeneity of variance (Cochran's test) without data transformation. Tukey's post hoc comparison of means was applied where appropriate. Further, to test for potential long-term acclimation effects, data on protein content and stable isotopes were analyzed after $210 \mathrm{~d}$ using nonparametric testing. A Kruskal-Wallis test was used to detect significant differences between origin and transplantation depths of the 15 surviving fragments after $210 \mathrm{~d}$ and the respective fragments after $30 \mathrm{~d}$, and a Mann-Whitney $U$ post hoc comparison was applied where appropriate. Further, a Wilcoxon matched-pairs signed-rank test was applied to test for differences between time points.

The factors "depth of origin," "transplantation depth," "mother colony," and "Symbiodinium type" were analyzed for their significance in distinguishing the coral samples using ANalyses Of SIMilarities (ANOSIM) with 9,999 permutations. Tissue composition of all transplants was analyzed using non-metric multidimensional scaling (nMDS) on Euclidian distances after $\log (x+1)$ transformation. SIMilarity PERcentage (SIMPER) analyses were conducted to examine the contribution of each variable to resemblance between transplantation depths. All multivariate statistics were computed with PRIMER version 6 software (Clarke and Gorley 2006).

\section{Results}

Environmental parameters

Light was the parameter that changed most with water depth; at noon, the mean light intensity at $5 \mathrm{~m}$ was $533.1 \pm 50.1 \mu \mathrm{mol}$ photons $\mathrm{m}^{-2} \mathrm{~s}^{-1}($ mean $\pm \mathrm{SE})$, and it 
decreased by around $50 \%$ at each depth interval to $323.1 \pm 23.0$ and $163.1 \pm 12.9 \mu \mathrm{mol}$ photons $\mathrm{m}^{-2} \mathrm{~s}^{-1}$ at 10 and $20 \mathrm{~m}$, respectively. All other physical parameters that could potentially influence coral photosynthesis and metabolism (i.e., temperature, inorganic nutrients, chlorophyll concentration, and TSM) did not differ between experimental depths (Electronic Supplementary Material, ESM Table 1).

Hard coral cover decreased from $47 \%$ at $5 \mathrm{~m}$ to $27 \%$ and $14 \%$ at 10 and $20 \mathrm{~m}$, respectively. Hard coral cover was mainly replaced by bare substrate, i.e., sand and rubble (ESM Fig. 1a). The highest density of $P$. verrucosa colo-

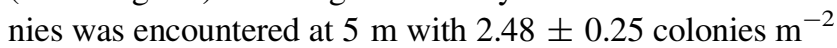
and decreased at 10 and $20 \mathrm{~m}$ to $1.18 \pm 0.25$ and $0.33 \pm 0.13$ colonies $\mathrm{m}^{-2}$, respectively. There was no significant difference in coral colony dimensions between depths (ANOVA, $p>0.05$ ). Nonetheless, we found the largest colonies at 5 and $10 \mathrm{~m}$ and the smallest at $20 \mathrm{~m}$ (ESM Fig. 1b). Of the total hard coral cover at 5 and $10 \mathrm{~m}$, $P$. verrucosa colonies contributed about $30 \%$ of the substrate category, while only $15 \%$ of hard coral cover at $20 \mathrm{~m}$ consisted of $P$. verrucosa.

\section{Coral host and Symbiodinium parameters}

After $30 \mathrm{~d}$ of transplantation, all fragments were alive and showed no visible signs of impairment. A global analysis of all photophysiological, pigment, and metabolic tissue parameters revealed a strong effect of transplantation depth (Table 1). There were significant differences in all fragments transplanted to $5 \mathrm{~m}$ compared to transplants at $10 \mathrm{~m}$ (pairwise ANOSIM, $r=0.355, p<0.001$ ) and $20 \mathrm{~m}$ (pairwise ANOSIM, $r=0.570, p<0.001$ ), while 10 and $20 \mathrm{~m}$ samples were not significantly different from each other (pairwise ANOSIM, $r=0.054, p>0.05$ ). We observed no significant differences between native transplants and non-native transplants at the same depth (Table 1). In line with this, mother colonies and main Symbiodinium type after $30 \mathrm{~d}$ did not show significant differences (Table 1).

Table 1 Contribution of transplantation depth, depth of origin, mother colony, and main Symbiodinium type to changes in 18 physiological parameters for P. verrucosa coral fragments after $30 \mathrm{~d}$ of cross-transplantation (ANOSIM (analysis of similarity), 9,999 permutations)

\begin{tabular}{lll}
\hline Source of variation & $r$ & $p$ value \\
\hline Transplantation depth & $\mathbf{0 . 3 2 1}$ & $\mathbf{< 0 . 0 0 1}$ \\
Depth of origin & 0.023 & n.s. \\
Mother colony & -0.059 & n.s. \\
Main Symbiodinium type & -0.015 & n.s. \\
\hline
\end{tabular}

n.s. not significant
A multivariate analysis showed that $P$. verrucosa fragments clustered according to transplantation depth (Fig. 1). The separation of the transplants from 5 to $10 \mathrm{~m}$ and from 5 to $20 \mathrm{~m}$ was driven by the photophysiological and pigment parameters, with each explaining ca. $40 \%$ of the dissimilarities within data (SIMPER, ESM Table 2). The minimum saturating irradiance, $E_{k}$, explained over $20 \%$ of the dissimilarities, and each of these two main categories (i.e., photophysiology and pigments) contained variables that contributed approximately another $10 \%\left(\mathrm{rETR}_{\max }\right.$, peridinin chl $a^{-1}$, Symbiodinium cell densities, chl a Symbiodinium cell $^{-1}$ ). In contrast, each of the metabolic parameters (i.e., total protein content, $\delta^{13} \mathrm{C}$ and $\delta^{15} \mathrm{~N}$ of host and Symbiodinium tissue) contributed only between 2 and $5 \%$ to the overall dissimilarity between transplant depths.

\section{Photophysiology}

All four in situ photophysiological parameters (i.e., $\mathrm{rETR}_{\max }, \mathrm{E}_{\mathrm{k}}, \alpha$, and $\Delta F / F_{m}{ }^{\prime}$ ) were significantly different between transplantation depths (Table 2). Relative ETR $_{\text {max }}$ and $E_{k}$ significantly decreased while $\alpha$ significantly increased with transplantation depth (Fig. 2). $\Delta F / F_{m}{ }^{\prime}$ was significantly decreased in all fragments transplanted to $5 \mathrm{~m}$ when compared to the 10- and 20-m transplantation depths (Tukey's HSD, both $p<0.001$ ), which were also significantly different from each other (Tukey's HSD, $p<0.05$ ). In contrast to all previous parameters though, there was a significant difference between depths of origin, as fragments originating at $20 \mathrm{~m}$ overall maintained higher $\Delta F / F_{m}{ }^{\prime}$ compared to fragments from $5 \mathrm{~m}$ (Tukey's HSD, $p<0.005$; Fig. 2). At the time of in situ measurements, all transplants at 5 and $10 \mathrm{~m}$ had reached light saturation with regard to the maximum light intensity measured during the CTD casts at noon (i.e., the minimum light saturating irradiance $E_{k}$ is lower than the ambient light at noon), while transplants at $20 \mathrm{~m}$ were still far below light saturation at noon.

Symbiodinium densities and pigment content

The Symbiodinium pigment profiles were a good predictor of transplantation depth (Table 2; ESM Table 2). All transplants at $20 \mathrm{~m}$ had significantly increased chlorophyll $a$ content compared to 5 and $10 \mathrm{~m}$ (Tukey's HSD, $p<0.001$ and $p<0.05$, respectively), while the pool size of the photoprotective xanthophylls, ddx (Tukey's HSD, both $p<0.05$ ), and dtx (Tukey's HSD, both $p<0.005$ ) was decreased (Table 2; Fig. 2), which led to the shift in the ratio of photoprotective to light-harvesting pigments. The significant differences in xanthophyll cycle pigment content with depth were not paralleled by xanthophyll de- 
Fig. 1 Non-metric multidimensional scaling (nMDS) plot displaying similarities of $45 P$. verrucosa fragments from three depths after $30 \mathrm{~d}$ of crosstransplantation taking 18 coral host and Symbiodinium parameters into account. Different shades (white: $5 \mathrm{~m}$, gray: $10 \mathrm{~m}$, black: $20 \mathrm{~m}$ ) denote transplantation depths, and different shapes (triangles: $5 \mathrm{~m}$, diamonds: $10 \mathrm{~m}$, circles: $20 \mathrm{~m}$ ) indicate depths of origin. The stress value denotes the goodness of fit. Vectors display the physiological parameters contributing strongest to the observed pattern

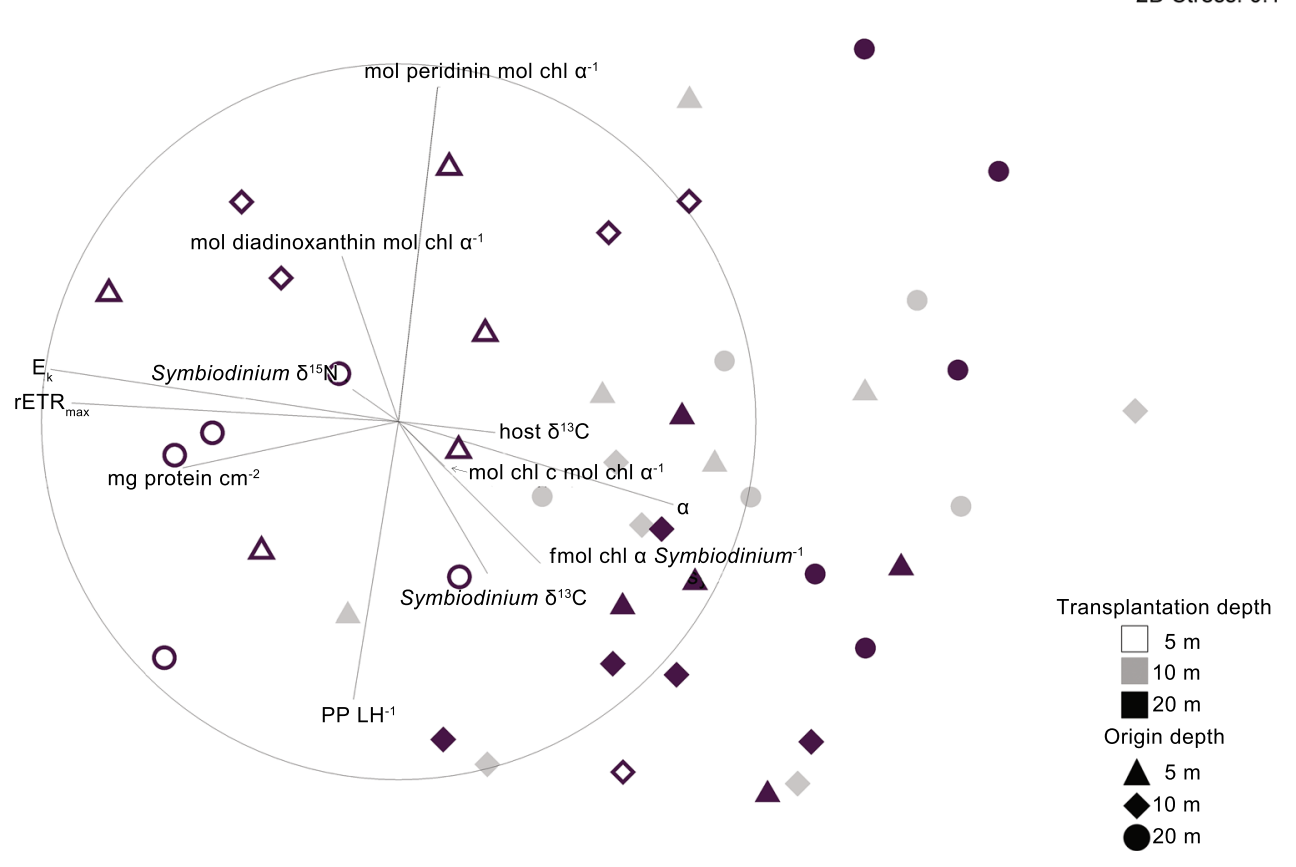

epoxidation (Table 2). There was also no significant difference in Symbiodinium cell densities between transplantation depths or depths of origin (Table 2). The peridinin chl $a$ ratio was among the most important explanatory variables in the multivariate statistics (ESM Table 2) and exhibited a significant interaction term (Table 2; Fig. 2). Fragments originating from $20 \mathrm{~m}$ had the highest peridinin chl $a$ ratio, which decreased when they were exposed to higher light levels. Conversely, fragments originating from the high- and intermediate-light environments at 5 and $10 \mathrm{~m}$ had decreased peridinin chl $a$ ratios when transplanted to lower light.

\section{Metabolic parameters}

Several metabolic parameters were significantly different between fragments transplanted at $5 \mathrm{~m}$ and those at 10 and $20 \mathrm{~m}$ (Tables 2, 3; ESM Table 2). Total protein content after $30 \mathrm{~d}$ was highest in transplants at $5 \mathrm{~m}$ and significantly decreased in transplants at 10 and $20 \mathrm{~m}$ (Tukey's HSD, $p<0.01$ and $p<0.005$, respectively; Fig. 2). The pattern was similar after $210 \mathrm{~d}$, with $5 \mathrm{~m}$ transplants containing significantly more protein than the $20 \mathrm{~m}$ transplants (Mann-Whitney $U, p<0.005$; Table 3). Transplantation depth also influenced $\delta^{13} \mathrm{C}$. In host tissues, $\delta^{13} \mathrm{C}$ was significantly decreased in transplants at $20 \mathrm{~m}$ compared to transplants at 10 and $5 \mathrm{~m}$ after $30 \mathrm{~d}$ (Tukey's HSD, $p<0.01$ and $p<0.005$, respectively). In Symbiodinium, $\delta^{13} \mathrm{C}$ was significantly decreased in transplants at $20 \mathrm{~m}$ compared to $5 \mathrm{~m}$ over the whole experimental period (post hoc tests for 30 and $210 \mathrm{~d}$, both $p<0.05$; Fig. 2; Table 3 ).
Generally, $\delta^{13} \mathrm{C}$ was higher in Symbiodinium than in host tissue. There was no influence of water depth on $\delta^{15} \mathrm{~N}$ in the host. In contrast, Symbiodinium cells originating at $5 \mathrm{~m}$ had significantly increased $\delta^{15} \mathrm{~N}$ compared to those originating at $10 \mathrm{~m}$ after $30 \mathrm{~d}$ (Tukey's HSD, $p<0.05$ ), causing a significant effect of depth of origin (Table 2; Fig. 2). The ratio of carbon to nitrogen $(\mathrm{C}: \mathrm{N})$ was stable across all samples (Table 2) and was double in Symbiodinium $(9.4 \pm 0.3)$ compared to host tissue $(5.1 \pm 0.1)$. Repeated sampling of metabolic parameters after 30 and $210 \mathrm{~d}$ showed no significant differences in acclimation in regard to transplantation depths between both time points indicating that "full" acclimation was accomplished after $30 \mathrm{~d}$ (Table 3). Nevertheless, a significant difference between time points for the parameters Symbiodinium $\delta^{13} \mathrm{C}, \delta^{15} \mathrm{~N}$, and host $\mathrm{C}: \mathrm{N}$, irrespective of transplantation depth and depth of origin, was observed (Table 3).

\section{Symbiodinium community composition}

Using ITS2-DGGE analysis, we identified six distinct Symbiodinium types (GenBank accession (GBA) KF620356-61). The most abundant species over all samples was Symbiodinium microadriaticum (sensu type A1; Fig. 3). Symbiodinium microadriaticum (GBA AF333505, LaJeunesse 2001) has a global distribution and is prevalent in corals from the Red Sea (data not shown). The second most abundant species was widespread Symbiodinium trenchi (sensu type D1a), which was often detected as a less abundant type along $S$. microadriaticum. Symbiodinium trenchi has been described in several coral species over 
Table 2 Differences between "depth of origin" and "transplantation depth" (5, 10, $20 \mathrm{~m})$ for 18 coral host and Symbiodinium variables after $30 \mathrm{~d}$ of cross-transplantation (two-factorial analysis of variance (ANOVA))

\begin{tabular}{|c|c|c|c|c|c|c|c|c|}
\hline Source of variation & $d f$ & MS & $F$ & $p$ & $5 \mathrm{~m}$ & $10 \mathrm{~m}$ & $20 \mathrm{~m}$ & Summary \\
\hline \multicolumn{9}{|l|}{ Photophysiological parameter } \\
\hline \multicolumn{9}{|l|}{ Relative $\mathrm{ETR}_{\max }$} \\
\hline Origin & 2 & $1,180.3$ & 1.44 & n.s. & $122.358(9.930)$ & $117.842(8.203)$ & $109.603(8.898)$ & \\
\hline Transplantation & 2 & $8,660.8$ & 10.55 & $<0.001$ & $142.546(9.574)$ & $105.945(7.040)$ & $99.7543(5.121)$ & $(10=20)<5$ \\
\hline Origin $*$ transplantation & 4 & 564.8 & 0.69 & n.s. & & & & \\
\hline Error & 36 & 820.8 & & & & & & \\
\hline \multicolumn{9}{|c|}{ Minimum saturating irradiance $\left(\mathrm{E}_{\mathrm{k}} ; \mu \mathrm{mol}\right.$ photons $\left.\mathrm{m}^{-2} \mathrm{~s}^{-1}\right)$} \\
\hline Origin & 2 & 2.30 & 0.42 & n.s. & $348.936(36.742)$ & $317.168(29.038)$ & $367.946(57.290)$ & \\
\hline Transplantation & 2 & 207.83 & 37.51 & $<0.001$ & $499.984(40.475)$ & $271.871(20.204)$ & $248.691(14.861)$ & $(10=20)<5$ \\
\hline Origin $*$ transplantation & 4 & 19.89 & 3.59 & 0.015 & & & & \\
\hline Error & 36 & 5.54 & & & & & & \\
\hline \multicolumn{9}{|c|}{ Effective quantum yield $\left(\Delta F / F_{m}{ }^{\prime}\right)$} \\
\hline Origin & 2 & 0.01 & 7.46 & 0.002 & $0.571(0.025)$ & $0.572(0.023)$ & $0.585(0.023)$ & $(5=10)<20$ \\
\hline Transplantation & 2 & 0.10 & 131.2 & $<0.001$ & $0.522(0.024)$ & $0.566(0.024)$ & $0.640(0.004)$ & $(10=20)>5$ \\
\hline Origin $*$ transplantation & 4 & 0.00 & 5.9 & 0.001 & & & & \\
\hline Error & 36 & 0.00 & & & & & & \\
\hline \multicolumn{9}{|l|}{ Light use efficiency $(\alpha)$} \\
\hline Origin & 2 & 0.00 & 3.04 & n.s. & $0.365(0.012)$ & $0.381(0.010)$ & $0.361(0.022)$ & \\
\hline Transplantation & 2 & 0.05 & 62.85 & $<0.001$ & $0.304(0.012)$ & $0.393(0.007)$ & $0.407(0.007)$ & $(10=20)>5$ \\
\hline Origin $*$ transplantation & 4 & 0.00 & 6.02 & 0.001 & & & & \\
\hline Error & 36 & 0.00 & & & & & & \\
\hline \multicolumn{9}{|l|}{ Pigment parameters } \\
\hline \multicolumn{9}{|l|}{ pmol chl a Symbiodinium $^{-1}$} \\
\hline Origin & 2 & 0.00 & 0.06 & n.s. & $1.437(0.107)$ & $1.488(0.121)$ & $1.466(0.122)$ & \\
\hline Transplantation & 2 & $\mathbf{0 . 0 0}$ & 11.6 & $<0.001$ & $1.157(0.064)$ & $1.413(0.087)$ & $1.822(0.115)$ & $5<10<20$ \\
\hline Origin $*$ transplantation & 4 & 0.00 & 0.47 & n.s. & & & & \\
\hline Error & 36 & 0.00 & & & & & & \\
\hline \multicolumn{9}{|c|}{ mol diadinoxanthin mol $\operatorname{chl} a^{-1}$} \\
\hline Origin & 2 & 0.00 & 1.59 & n.s. & $0.361(0.007)$ & $0.363(0.008)$ & $0.373(0.006)$ & \\
\hline Transplantation & 2 & 0.01 & 10.96 & $<0.001$ & $0.378(0.005)$ & $0.374(0.005)$ & $0.345(0.007)$ & $(5=10)>20$ \\
\hline Origin $*$ transplantation & 4 & 0.00 & 1.74 & n.s. & & & & \\
\hline Error & 36 & 0.00 & & & & & & \\
\hline \multicolumn{9}{|c|}{ mol diatoxanthin mol $\operatorname{chl} a^{-1}$} \\
\hline Origin & 2 & 0.00 & 0.93 & n.s. & $0.044(0.003)$ & $0.048(0.005)$ & $0.0418(0.003)$ & \\
\hline Transplantation & 2 & 0.00 & 4.73 & 0.015 & $0.048(0.003)$ & $0.049(0.004)$ & $0.037(0.002)$ & $(5=10)>20$ \\
\hline Origin $*$ transplantation & 4 & 0.00 & 1.34 & n.s. & & & & \\
\hline Error & 36 & 0.00 & & & & & & \\
\hline \multicolumn{9}{|l|}{ mol peridinin mol chl $a^{-1}$} \\
\hline Origin & 2 & 0.18 & 1.6 & n.s. & $1.060(0.201)$ & $0.899(0.205)$ & $1.337(0.278)$ & \\
\hline Transplantation & 2 & 0.12 & 1.12 & n.s. & $1.223(0.190)$ & $1.115(0.208)$ & $0.935(0.275)$ & \\
\hline Origin $*$ transplantation & 4 & 0.44 & 4.05 & 0.008 & & & & \\
\hline Error & 36 & 0.11 & & & & & & \\
\hline \multicolumn{9}{|l|}{ Xanthophyll de-epoxidation } \\
\hline Origin & 2 & 0.00 & 1.44 & n.s. & $0.107(0.005)$ & $0.113(0.008)$ & $0.100(0.006)$ & \\
\hline Transplantation & 2 & 0.00 & 2.89 & n.s. & $0.112(0.006)$ & $0.114(0.008)$ & $0.095(0.004)$ & \\
\hline Origin $*$ transplantation & 4 & 0.00 & 1.34 & n.s. & & & & \\
\hline Error & 36 & 0.00 & & & & & & \\
\hline
\end{tabular}


Table 2 continued

\begin{tabular}{|c|c|c|c|c|c|c|c|c|}
\hline Source of variation & $d f$ & MS & $F$ & $p$ & $5 \mathrm{~m}$ & $10 \mathrm{~m}$ & $20 \mathrm{~m}$ & Summary \\
\hline \multicolumn{9}{|c|}{ Photoprotective pigments light-harvesting pigments ${ }^{-1}$} \\
\hline Origin & 2 & 0.00 & 0.65 & n.s. & $0.356(0.012)$ & $0.348(0.021)$ & $0.378(0.012)$ & \\
\hline Transplantation & 2 & 0.00 & 0.42 & n.s. & $0.384(0.017)$ & $0.371(0.015)$ & $0.328(0.011)$ & \\
\hline Origin $*$ transplantation & 4 & 0.01 & 1.9 & n.s. & & & & \\
\hline Error & 36 & 0.00 & & & & & & \\
\hline \multicolumn{9}{|l|}{ Symbiodinium $\mathrm{cm}^{-2} * 10^{6}$} \\
\hline Origin & 2 & 2.01 & 1.42 & n.s. & $3.144(0.208)$ & $3.869(0.357)$ & $3.421(0.315)$ & \\
\hline Transplantation & 2 & 0.03 & 0.02 & n.s. & $3.516(0.293)$ & $3.426(0.364)$ & $3.492(0.266)$ & \\
\hline Origin $*$ transplantation & 4 & 1.49 & 1.06 & n.s. & & & & \\
\hline Error & 36 & 1.41 & & & & & & \\
\hline \multicolumn{9}{|l|}{$\operatorname{mol~chl~} c_{2} \operatorname{mol~chl~} a^{-1}$} \\
\hline Origin & \multirow{2}{*}{\multicolumn{4}{|c|}{ Assumptions not met }} & $0.208(0.034)$ & $0.275(0.058)$ & $0.183(0.045)$ & \\
\hline Transplantation & & & & & $0.202(0.045)$ & $0.225(0.047)$ & $0.241(0.050)$ & \\
\hline \multicolumn{9}{|l|}{ mol ß-carotene mol chl $a^{-1}$} \\
\hline Origin & \multirow{2}{*}{\multicolumn{4}{|c|}{ Assumptions not met }} & $0.021(0.002)$ & $0.021(0.004)$ & $0.027(0.002)$ & \\
\hline Transplantation & & & & & $0.027(0.002)$ & $0.022(0.004)$ & $0.020(0.003)$ & \\
\hline \multicolumn{9}{|l|}{$\begin{array}{l}\text { Metabolic parameters } \\
\text { mg Total protein } \mathrm{cm}^{-2}\end{array}$} \\
\hline Origin & 2 & 0.09 & 1.495 & n.s. & $1.465(0.061)$ & $1.478(0.069)$ & $1.332(0.089)$ & \\
\hline Transplantation & 2 & 0.47 & 7.736 & 0.002 & $1.627(0.067)$ & $1.331(0.057)$ & $1.307(0.070)$ & $(10=20)<5$ \\
\hline Origin $*$ transplantation & 4 & 0.06 & 0.928 & n.s. & & & & \\
\hline Error & 36 & 0.06 & & & & & & \\
\hline \multicolumn{9}{|l|}{$\delta^{13} \mathrm{C}$ host } \\
\hline Origin & 2 & 0.89 & 1.04 & n.s. & $-16.051(0.305)$ & $-16.028(0.287)$ & $-16.462(0.227)$ & \\
\hline Transplantation & 2 & 6.83 & 7.97 & 0.001 & $-15.732(0.214)$ & $-15.852(0.226)$ & $-16.956(0.271)$ & $(5=10)>20$ \\
\hline Origin $*$ transplantation & 4 & 0.76 & 0.89 & n.s. & & & & \\
\hline Error & 36 & 0.86 & & & & & & \\
\hline \multicolumn{9}{|l|}{$\delta^{13} \mathrm{C}$ Symbiodinium } \\
\hline Origin & 2 & 0.00 & 0.54 & n.s. & $-12.933(0.494)$ & $-13.480(0.375)$ & $-13.604(0.339)$ & \\
\hline Transplantation & 2 & 0.01 & 4.52 & 0.018 & $-12.429(0.326)$ & $-13.388(0.369)$ & $-14.200(0.403)$ & $(10=20)<5$ \\
\hline Origin $*$ transplantation & 4 & 0.00 & 0.13 & n.s. & & & & \\
\hline Error & 36 & 0.00 & & & & & & \\
\hline \multicolumn{9}{|l|}{$\delta^{15} \mathrm{~N}$ host } \\
\hline Origin & 2 & 0.26 & 1.252 & n.s. & $2.697(0.144)$ & $2.820(0.150)$ & $3.046(0.079)$ & \\
\hline Transplantation & 2 & 0.02 & 0.087 & n.s. & $2.896(0.146)$ & $2.727(0.143)$ & $2.932(0.102)$ & \\
\hline Origin $*$ transplantation & 4 & 0.19 & 0.94 & n.s. & & & & \\
\hline Error & 36 & 0.21 & & & & & & \\
\hline \multicolumn{9}{|l|}{$\delta^{15} \mathrm{~N}$ Symbiodinium } \\
\hline Origin & 2 & 0.38 & 3.59 & 0.038 & $2.847(0.078)$ & $2.421(0.147)$ & $2.557(0.095)$ & $(10=20)<5$ \\
\hline Transplantation & 2 & 0.05 & 0.43 & n.s. & $2.607(0.098)$ & $2.634(0.122)$ & $2.601(0.138)$ & \\
\hline Origin $*$ transplantation & 4 & 0.20 & 1.937 & n.s. & & & & \\
\hline Error & 36 & 0.11 & & & & & & \\
\hline \multicolumn{9}{|l|}{$\mathrm{C}: \mathrm{N}$ host } \\
\hline Origin & 2 & 0.44 & 0.07 & n.s. & $4.989(0.922)$ & $5.137(0.088)$ & $5.010(0.047)$ & \\
\hline Transplantation & 2 & 1.05 & 0.18 & n.s. & $5.055(0.084)$ & $5.144(0.068)$ & $4.936(0.077)$ & \\
\hline Origin $*$ transplantation & 4 & 2.17 & 0.36 & n.s. & & & & \\
\hline Error & 36 & 6.03 & & & & & & \\
\hline
\end{tabular}


Table 2 continued

\begin{tabular}{lrllllll}
\hline Source of variation & $d f$ & MS & $F$ & $p$ & $5 \mathrm{~m}$ & $10 \mathrm{~m}$ & $20 \mathrm{~m}$ \\
\hline C:N Symbiodinium & & & & & & & Summary \\
$\quad$ Origin & 2 & 0.096 & 1.10 & n.s. & $9.262(0.564)$ & $9.605(0.797)$ & $9.307(0.258)$ \\
Transplantation & 2 & 0.163 & 1.86 & n.s. & $9.476(0.547)$ & $9.679(0.762)$ & $9.003(0.427)$ \\
Origin * transplantation & 4 & 0.092 & 1.05 & n.s. & & \\
$\quad$ Error & 36 & 0.088 & & & & &
\end{tabular}

Values of each physiological parameter (mean \pm SE) are given for depth of origin (origin) and transplantation depths (indicated by $\mathrm{m}$ depth). Significant values $(p<0.05)$ are in bold, and the differences between the three depths are summarized in the last column n.s. not significant

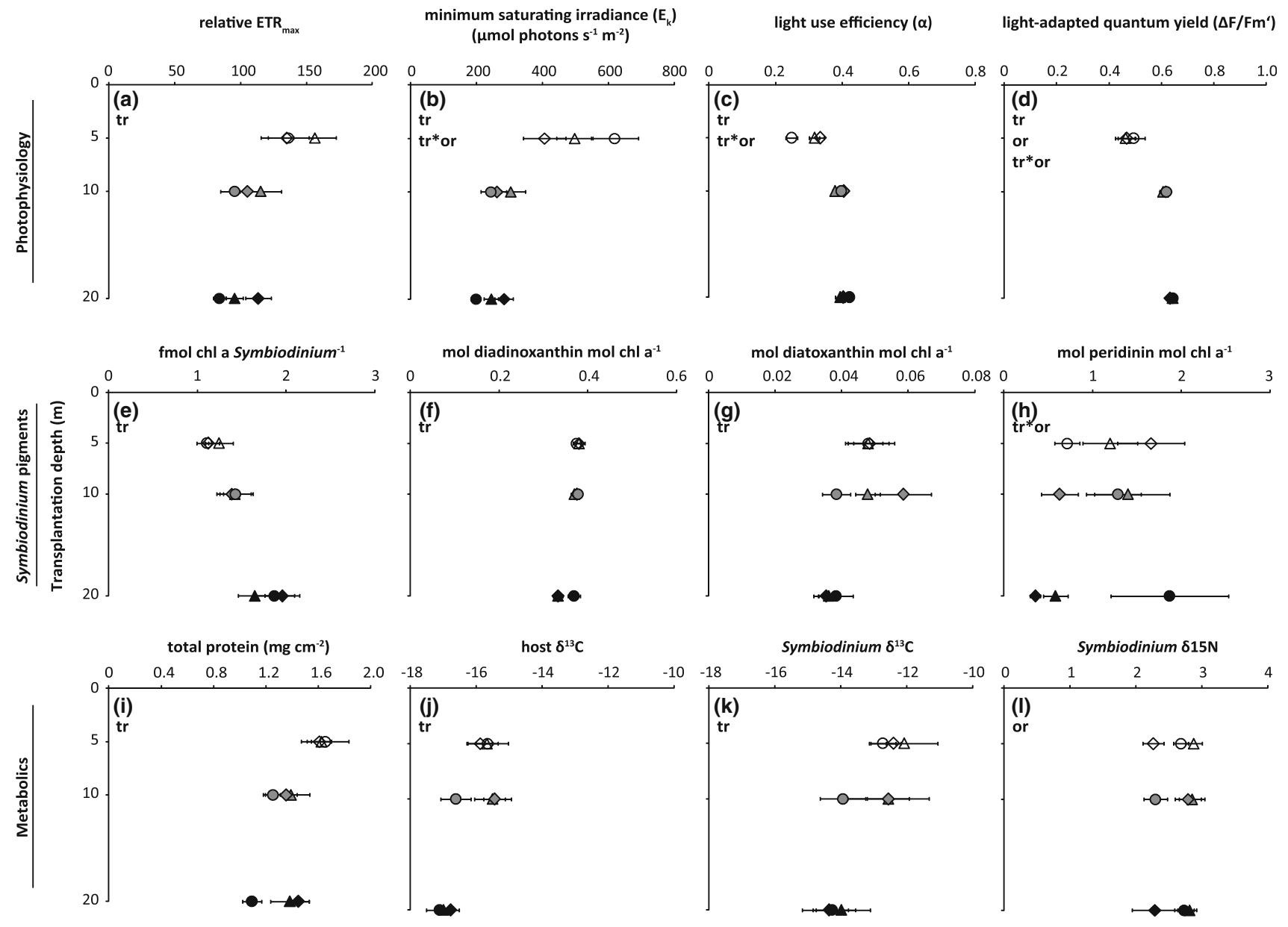

Fig. 2 Photophysiological (first row, a-d), Symbiodinium pigment (second row, $\mathbf{e}-\mathbf{h}$ ), and metabolic (third row, $\mathbf{i}-\mathbf{l}$ ) parameters of $P$. verrucosa after a $30 \mathrm{~d}$ of cross-depth transplantation experiment. Symbols represent the depths of origin (triangles: $5 \mathrm{~m}$, diamonds: $10 \mathrm{~m}$, circles: $20 \mathrm{~m}$ ), and colors refer to the transplantation depths

large geographical ranges (GBA GQ268420 Thornhill et al. 2009; JN558080, Pochon et al. 2012). More than $25 \%$ of mother colonies exhibited Symbiodinium from clade C during at least one time point of the experiment (Fig. 3). These were type C\#, known from Seriatopora hystrix from east and west Australia (GBA JF298202, van Oppen et al. 2011), (white: $5 \mathrm{~m}$, gray: $10 \mathrm{~m}$, black: $20 \mathrm{~m}$ ). Significant differences between depths of origin (or), transplant depths (tr), or the interaction of the two (tr*or) are indicated below each individual graph label (two-factorial ANOVA, $p<0.05$; Table 2); $n=5$, error bars $=\mathrm{SE}$

C15, known from Porites spp. in the Central Pacific (GBA JX394104, Padilla-Gamiño et al. 2012), and C116, identical to Symbiodinium found in Favites from the Western Indian Ocean (GBA GU111899, LaJeunesse et al. 2010). In one fragment at one time point, the presence of Symbiodinium minutum (sensu type B1), known from the 
Table 3 Differences in metabolic tissue parameters for 15 fragments compared after 30 and $210 \mathrm{~d}$ of cross-transplantation (5, 10, 20 m)

\begin{tabular}{|c|c|c|c|c|c|c|c|c|c|}
\hline Source of variation & $\mathrm{H}$ & $\mathrm{Z}$ & $p$ & $5 \mathrm{~m}$ & $10 \mathrm{~m}$ & $20 \mathrm{~m}$ & $30 \mathrm{~d}$ & $210 \mathrm{~d}$ & Summary \\
\hline \multicolumn{10}{|c|}{$\mathrm{mg}$ Total protein $\mathrm{cm}^{-2}$} \\
\hline Depth of origin & 3.296 & & n.s. & $1.54(0.04)$ & $1.42(0.09)$ & $1.25(0.16)$ & & & \\
\hline Transplant depth & 7.604 & & 0.022 & $1.59(0.04)$ & $1.39(0.15)$ & $1.29(0.08)$ & & & $(5=10)>20$ \\
\hline Time & & 0.057 & n.s. & & & & $1.44(0.06)$ & $1.44(0.09)$ & \\
\hline \multicolumn{10}{|l|}{$\delta^{13} \mathrm{C}$ host } \\
\hline Depth of origin & 5.515 & & n.s. & $-15.6(0.27)$ & $-15.9(0.18)$ & $-17.2(0.63)$ & & & \\
\hline Transplant depth & 2.125 & & n.s. & $-15.6(0.25)$ & $-16.0(0.32)$ & $-16.4(0.34)$ & & & \\
\hline Time & & 1.306 & n.s. & & & & $-15.8(0.20)$ & $-16.1(0.29)$ & \\
\hline \multicolumn{10}{|l|}{$\delta^{13} \mathrm{C}$ Symbiodinium } \\
\hline Depth of origin & 0.163 & & n.s. & $-13.8(0.30)$ & $-14.0(0.32)$ & $-14.0(0.60)$ & & & \\
\hline Transplant depth & 6.242 & & 0.044 & $-13.4(0.28)$ & $-13.7(0.40)$ & $-14.6(0.33)$ & & & $(5=10)>20$ \\
\hline Time & & 3.408 & 0.001 & & & & $13.5(0.29)$ & $14.3(0.26)$ & $30 \mathrm{~d}>210 \mathrm{~d}$ \\
\hline \multicolumn{10}{|l|}{$\delta^{15} \mathrm{~N}$ host } \\
\hline Depth of origin & 3.014 & & n.s. & $2.72(0.09)$ & $2.64(0.11)$ & $2.94(0.08)$ & & & \\
\hline Transplant depth & 3.914 & & n.s. & $2.81(0.08)$ & $2.44(0.15)$ & $2.80(0.13)$ & & & \\
\hline Time & & 1.477 & n.s. & & & & $2.83(0.10)$ & $2.59(0.09)$ & \\
\hline \multicolumn{10}{|l|}{$\delta^{15} \mathrm{~N}$ Symbiodinium } \\
\hline Depth of origin & 5.532 & & n.s. & $2.49(0.17)$ & $2.04(0.12)$ & $2.58(0.06)$ & & & \\
\hline Transplant depth & 1.884 & & n.s. & $2.13(0.17)$ & $2.43(0.21)$ & $2.28(0.13)$ & & & \\
\hline Time & & 2.101 & 0.036 & & & & $2.61(0.11)$ & $1.91(0.10)$ & $30 \mathrm{~d}>210 \mathrm{~d}$ \\
\hline \multicolumn{10}{|l|}{ C:N host } \\
\hline Depth of origin & 5.040 & & n.s. & $5.39(0.19)$ & $5.86(0.30)$ & $4.83(0.05)$ & & & \\
\hline Transplant depth & 3.051 & & n.s. & $5.76(0.40)$ & $5.73(0.17)$ & $5.22(0.21)$ & & & \\
\hline Time & & 3.237 & 0.001 & & & & $5.01(0.08)$ & $6.13(0.29)$ & $30 \mathrm{~d}<210 \mathrm{~d}$ \\
\hline \multicolumn{10}{|l|}{ C:N Symbiodinium } \\
\hline Depth of origin & 0.645 & & n.s. & $8.21(0.44)$ & $8.30(0.24)$ & $9.28(1.19)$ & & & \\
\hline Transplant depth & 2.735 & & n.s. & $7.95(0.26)$ & $8.43(0.57)$ & $8.92(0.46)$ & & & \\
\hline Time & & 0.738 & n.s. & & & & $8.72(0.43)$ & $8.08(0.21)$ & \\
\hline
\end{tabular}

Differences between depths of origin and transplantation depths were tested using Kruskal-Wallis $H$ test. Comparison of time points was conducted with Wilcoxon matched-pairs signed-rank test. Differences from Mann-Whitney $U$ post hoc comparison are summarized in the right column. Significant values $(p<0.05)$ are in bold, and the means $(\mathrm{SE})$ between depths and times are given; $\mathrm{H}=\mathrm{H}$ score Kruskal-Wallis $H$ test; $\mathrm{Z}=\mathrm{Z}$ score Wilcoxon matched-pairs signed-rank test

n.s. not significant

Caribbean (GBA FJ811928, DeSalvo et al. 2010), was detected in minor abundance.

During the length of the experiment, a shift of the main Symbiodinium type occurred 9 out of 89 times (Fig. 3). A permutation test did not show any significant differences in Symbiodinium composition with depth of origin or transplantation depth $(p>0.05)$. A change in the minor Symbiodinium types was observed at least once in half of the fragments, all of which but one originated at 5 and $10 \mathrm{~m}$. Furthermore, minor Symbiodinium changes occurred at similar frequencies in fragments from 5 to $10 \mathrm{~m}$ (permutation test, $p>0.05$ ), which were not significantly different between transplantation depths (permutation test, $p>0.05)$. The Symbiodinium community in fragments from $20 \mathrm{~m}$ seemed to be less diverse, and changes in background types occurred significantly less frequent than at 5 and $10 \mathrm{~m}$ (permutation test, $p<0.001$ and $p<0.05$, respectively). After $210 \mathrm{~d}, 15$ of the remaining 41 fragments survived (excluding lost ones), and there was no significant difference in mortality rates between depth of origin and transplantation depth (permutation test, $p>0.05)$.

\section{Discussion}

Corals are evolved to live in nutrient-depleted environments, where they are largely dependent on the photosynthetic output from Symbiodinium. Accordingly, in order to optimize photosynthetic output, fast acclimation to changing environmental conditions is imperative. Here, we tested the limits of physiological plasticity to different light 


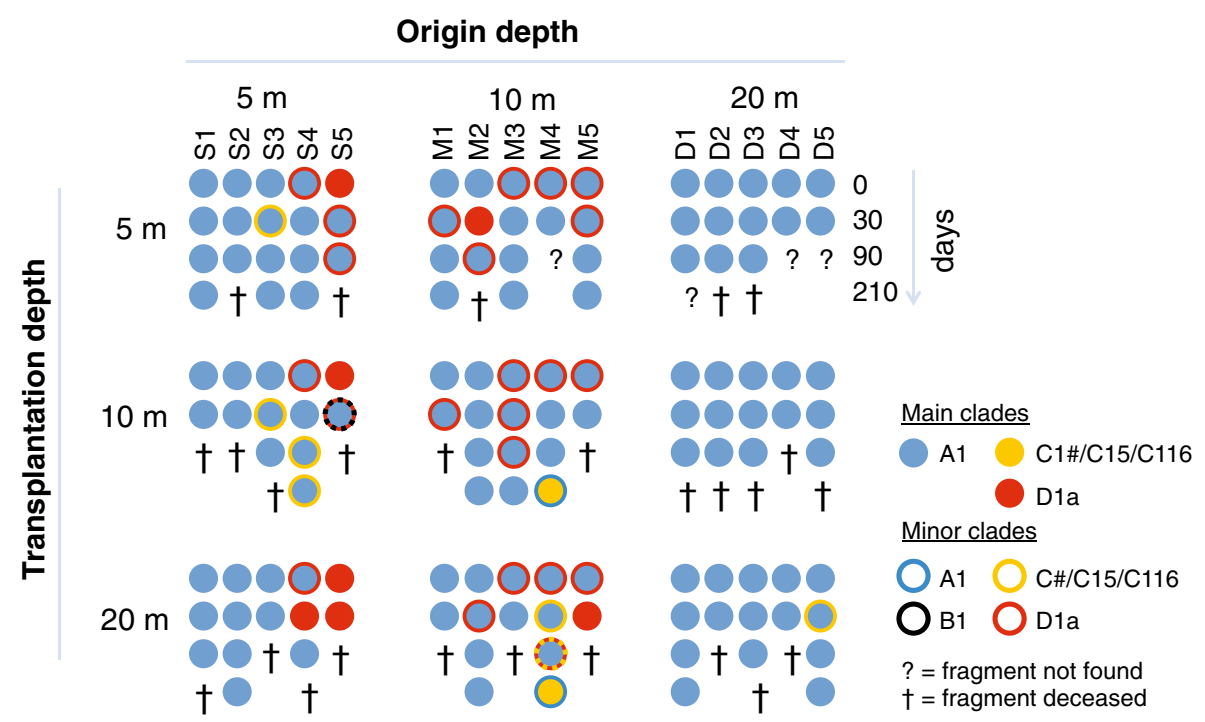

Fig. 3 ITS2-DGGE results of Symbiodinium community composition from $P$. verrucosa fragments during a cross-depth transplantation experiment. Each circle represents one sample at one time point. Each of the nine blocks denotes an experimental group with the depths of origin on the $x$-axis and the transplantation depths on the $y$-axis. Circles along a row represent fragments sampled at the same time at 0, 30, 90, and $210 \mathrm{~d}$. Circles in one column belong to a particular mother colony (S1-5, M1-5, and D1-5, respectively), whose fragments were transplanted to the three depths and sampled repeatedly. The main Symbiodinium types identified through sequencing of the

regimes in the hermatypic coral $P$. verrucosa by conducting cross-depth transplantation experiments and subsequent assaying of physiological parameters of the coral host and its Symbiodinium community.

In our study, photoacclimation to decreased light, i.e., depth, was driven by an increase in chl $a$ per Symbiodinium cell, while Symbiodinium cell numbers remained stable. These observations are in line with the hypothesis that the ability to change Symbiodinium cell densities may be dependent on the perforate versus imperforate nature of the species' skeleton (Kinzie et al. 1984). P. verrucosa, as a representative of an imperforate species, displays lower tissue volumes and is unable to modulate cell numbers. The increase in chl $a$ per Symbiodinium cell resulted in a lower ratio of the other light-harvesting pigments. This indicates an increase in the photosynthetic units (PSUs) per cell (Iglesias-Prieto and Trench 1997), rather than an increase in the size of the light-harvesting complexes with a stable number of PSUs (Falkowski and Dubinsky 1981; Kinzie et al. 1984).

Interestingly, peridinin chl $a$ ratio changed in the dependence of both, transplantation depth and depth of origin. The fact that this pattern is different from all other collected physiological data might be one of the reasons for its significance in the multivariate analysis. Physiologically, a change in peridinin chl $a^{-1}$ ratios can be indicative dominant DGGE bands are denoted by filled circles. If a colored ring is present around the main circle, it represents background types detected. In the two instances where multiple background types were detected, the ring is colored in both shades. Deceased fragments were excluded from the analysis, and the respective spaces are marked by a cross, while lost fragments are marked by a question mark. Symbiodinium types were used in accordance with species designations (i.e., Symbiodinium microadriaticum, sensu A1; Symbiodinium minutum, sensu B1; Symbiodinium trenchi, sensu D1a)

of functional changes in the PSUs (Iglesias-Prieto and Trench 1997), because peridinin is part of different LH pigment-protein complexes (Jeffrey and Haxo 1968). Fragments from $20 \mathrm{~m}$ depth of origin displayed reduced peridinin chl $a$ ratios when transplanted to shallower depths (i.e., 5 and $10 \mathrm{~m}$ ), which could be related to a decline of peridinin-chl proteins (4 peridinin/1 chl $a$; Hofmann et al. 1996) in favor of differential accumulation of chl $a-\operatorname{chl} c_{2}-$ peridinin protein complexes $\left(2 \mathrm{chl} a / 1 \mathrm{chl} c_{2} / 3\right.$ peridinin; Hiller et al. 1993). Changing concentrations of these pigment complexes as a response to high light exposure have been observed before in cultures of $S$. microadriaticum (Iglesias-Prieto and Trench 1997). The fact that this pattern is reversed in colonies from a shallow depth of origin when transplanted to a deeper depth is surprising and indicates diverging photoacclimation mechanisms between $S$. microadriaticum from shallow and deep habitats.

For PP activity, a reversed trend to that of chl $a$ was apparent: We observed increasing concentrations of photoprotective xanthophylls and rates of xanthophyll deepoxidation with higher light, indicating the activation of photoprotective pathways (Brown et al. 1999) that have been described in other Pocilloporids before (Krämer et al. 2013). From our data, we conclude that transplanted $P$. verrucosa fragments acclimated to their new light environment by storing more light-harvesting pigments per 
area, increasing their photosynthetic efficiency, and decreasing their minimum saturating irradiance when transplanted to deeper depths. Nonetheless, the relative maximum electron rate was significantly decreased in transplants at 10 and $20 \mathrm{~m}$, which indicates that the photosynthetic rate was not high enough to sustain protein energy reserves (McCloskey and Muscatine 1984; Cooper et al. 2011a).

Shifts in carbon and nitrogen stable isotopic ratios indicate the metabolic state and strategy of an organism (Muscatine et al. 1989). When exposed to lower light levels, $\delta^{13} \mathrm{C}$ in host and Symbiodinium tissue was reduced at $20 \mathrm{~m}$ after $210 \mathrm{~d}$, similar to the $\delta^{13} \mathrm{C}$ depletion observed in S. pistillata residing below $15 \mathrm{~m}$ (Alamaru et al. 2009). This observation could be explained either by lower photosynthetic rates, which enhance fractionation during carbon fixation (Swart et al. 2005), or by increased heterotrophic uptake of organic material low in $\delta^{13} \mathrm{C}$. The $\delta^{13} \mathrm{C}$ of heterotrophic sources in TSM from our water samples were around $-24 \%$. Heterotrophic carbon is mainly incorporated into the tissue as proteins (Ferrier-Pagès et al. 2003; Bachar et al. 2007). This is in contrast to autotrophic sources, which are commonly stored as fatty acid compounds and used for immediate energy requirements (Patton et al. 1977; Oku et al. 2003). Consequently, decreasing protein content in deeper corals indicates a lack of compensatory heterotrophy with depth, which corresponds with observations from other Red Sea corals (Alamaru et al. 2009). Another factor that may play a role in heterotrophic plasticity is the positive correlation of feeding rate and food density as observed for Pocillopora damicornis (Clayton and Lasker 1982; Anthony 1999; Palardy et al. 2006). However, in our experiment, we did not see a difference in TSM between experimental depths. Further, increased food supply resulting from stronger currents in deeper water is unlikely to explain the observed pattern as flows in reefs are usually wave-driven (Monismith 2007) and would hence rather result in higher feed fluxes for the shallow-water coral community. This conclusion is supported by unchanged $\delta^{15} \mathrm{~N}$ values, which we expect to become enriched with a higher heterotrophic/autotrophic ratio (Alamaru et al. 2009). Also, the carbon-tonitrogen $(\mathrm{C}: \mathrm{N})$ ratio in host and Symbiodinium tissues remained unchanged between depths throughout the duration of the transplantation experiment. As $\mathrm{C}: \mathrm{N}$ ratios are a good proxy for the proportion of lipids and carbohydrates to proteins, unchanged $\mathrm{C}: \mathrm{N}$ ratios of samples containing less protein are likely also decreased in autotrophic primary and secondary products (i.e., carbohydrates and lipids). However, there was a significant effect of time (i.e., between 30 and 210 d) on stable isotope composition that we attribute to seasonal differences as all fragments were affected, irrespective of depth of origin or transplantation depth (Nahon et al. 2013).

It has been shown that decreased autotrophy under low light fosters heterotrophy in $P$. damicornis (Palardy et al. 2005) and other coral species (Ferrier-Pagès et al. 1998; Palardy et al. 2008; Lesser et al. 2010). However, despite the strong photoacclimatory signal in our data, $P$. verrucosa did not compensate for reduced light levels through an increased intake of heterotrophic energy sources (i.e., by feeding). Flexibility in carbon acquisition may be a trait determining a species' ecological niche and distribution range (Hoogenboom et al. 2010). This offers a possible explanation for the narrow depth distribution of $P$. verru$\cos a$ and the decreasing number of colonies with depth in the Red Sea. Our experimental data provide strong evidence that $P$. verrucosa has low heterotrophic plasticity. Heterotrophic plasticity is species-specific, and colony growth form and polyp size influence prey capture rates (Anthony 1999; Anthony and Fabricius 2000; Palardy et al. 2005). As seems to be the case for $P$. verrucosa, low heterotrophic plasticity has been shown for other Pocillopora species (Wellington 1982; Palardy et al. 2005), making these species particularly vulnerable to disturbance caused by environmental change (Roder et al. 2010). For instance, during bleaching events that are predicted to occur more frequently under global warming, increased heterotrophy significantly contributes to stress resistance and recovery (Grottoli et al. 2006; Rodrigues and Grottoli 2007). Furthermore, other Red Sea corals also displayed low rates of heterotrophy (Alamaru et al. 2009), suggesting that the particularly oligotrophic environmental settings in the Red Sea may exacerbate this tendency by lacking heterotrophic food sources in sufficient density.

The association with different Symbiodinium types may confer a metabolic advantage on their respective hosts in a given environment (Little et al. 2004; Cantin et al. 2009; Cooper et al. 2011a, b) and broadens the ecological niche of corals (Cooper et al. 2011c). While in some species depth-dependent shifts of Symbiodinium types take place (Frade et al. 2008b; Lesser et al. 2010; Cooper et al. 2011a), several Pocillopora species display rather stable relationships with only a few Symbiodinium types, likely due to the vertical transmission of Symbiodinium in this genus (LaJeunesse et al. 2008). In this regard, it is not surprising that all but one of the transplant mother colonies in this experiment hosted the same main Symbiodinium type (i.e., S. microadriaticum, sensu type A1). In agreement with our observations, there have been few reports of acclimatory changes in Symbiodinium types (Berkelmans and van Oppen 2006; Jones et al. 2008). Further, corals sampled over time reveal stable Symbiodinium type associations (LaJeunesse et al. 2008). 
This is also true when analyzing Symbiodinium composition of corals recovering from stress events (McGinley et al. 2012) or upon changing environmental conditions (Bongaerts et al. 2011). On the other hand, almost half of all colonies in our experiment associated with a distinct Symbiodinium background type. This seems to be a common observation in Pocillopora colonies. For instance, a study by McGinley et al. (2012) observed background shuffling of Symbiodinium types in $30 \%$ of Pocillopora colonies investigated.

Taken together, our results provide insights into the limits of physiological plasticity and consequently the acclimation potential of $P$. verrucosa to different light regimes or depths. P. verrucosa seems to be photophysiologically well adapted to a high light environment where it is most abundant. In contrast, the heterotrophic and autotrophic plasticity of $P$. verrucosa may not be sufficient to overcome decreasing light levels in deeper water, as demonstrated by depleted protein reserves, shifting stable isotopic ratios, and stable Symbiodinium community composition. This offers an explanation for the narrow depth distribution of $P$. verrucosa when compared to species displaying either higher heterotrophic plasticity, or variable host-Symbiodinium relationships (promoting autotrophic plasticity). We conclude that $P$. verrucosa will be a species particularly vulnerable to sudden changes in underwater light fields, resulting from processes such as increased turbidity caused by coastal development. Additionally, the absence of heterotrophic plasticity, contributing to stress resistance otherwise, classifies this species as vulnerable to the consequences of environmental change.

Acknowledgments We would like to thank KAUST CMOR staff and boat crews for their support in the field, R. Eilers for briefing and supervision at the HPLC, G. Schneider for statistical support with the multiple permutation tests, E. Banguera for introduction to the DGGE technique, the Bioscience Core Lab at KAUST for sequencing, and the editor and reviewers for their insightful comments. MZ was financially supported by "LOEWE" funding scheme of Hesse's Ministry of Higher Education, Research, and the Arts. Additional financial support was provided by KAUST baseline funds to CRV.

Open Access This article is distributed under the terms of the Creative Commons Attribution License which permits any use, distribution, and reproduction in any medium, provided the original author(s) and the source are credited.

\section{References}

Alamaru A, Loya Y, Brokovich E, Yam R, Shemesh A (2009) Carbon and nitrogen utilization in two species of Red Sea corals along a depth gradient: insights from stable isotope analysis of total organic material and lipids. Geochim Cosmochim Acta 73:5333-5342

Anthony KRN (1999) Coral suspension feeding on fine particulate matter. J Exp Mar Biol Ecol 232:85-106
Anthony KRN, Fabricius KE (2000) Shifting roles of heterotrophy and autotrophy in coral energetics under varying turbidity. J Exp Mar Biol Ecol 252:221-253

Auld JR, Agrawal AA, Relyea RA (2010) Re-evaluating the costs and limits of adaptive phenotypic plasticity. Proc R Soc Lond B Biol Sci 277:503-511

Bachar A, Achituv Y, Pasternak Z, Dubinsky Z (2007) Autotrophy versus heterotrophy: the origin of carbon determines its fate in a symbiotic sea anemone. J Exp Mar Biol Ecol 349:295-298

Berkelmans R, van Oppen MJH (2006) The role of zooxanthellae in the thermal tolerance of corals: a 'nugget of hope' for coral reefs in an era of climate change. Proc R Soc Lond B Biol Sci 273:2305-2312

Bongaerts P, Riginos C, Hay K, van Oppen M, Hoegh-Guldberg O, Dove S (2011) Adaptive divergence in a scleractinian coral: physiological adaptation of Seriatoporahystrix to shallow and deep reef habitats. BMC Evol Biol 11:303

Brown BE (1997) Adaptations of reef corals to physical environmental stress. Adv Mar Biol 31:221-299

Brown BE, Ambarsari I, Warner ME, Fitt WK, Dunne RP, Gibb SW, Cummings DG (1999) Diurnal changes in photochemical efficiency and xanthophyll concentrations in shallow water reef corals: evidence for photoinhibition and photoprotection. Coral Reefs 18:99-105

Cantin NE, van Oppen MJH, Willis BL, Mieog JC, Negri AP (2009) Juvenile corals can acquire more carbon from high-performance algal symbionts. Coral Reefs 28:405-414

Clarke K, Gorley R (2006) PRIMER v6: User Manual/Tutorial. PRIMER-E, Plymouth

Clayton WS, Lasker HR (1982) Effects of light and dark treatments on feeding by the reef coral Pocilloporadamicornis (Linnaeus). J Exp Mar Biol Ecol 63:269-279

Coleman AW, Suarez A, Goff LJ (1994) Molecular delineation of species and syngens in volvocacean green algae (Chlorophyta). J Phycol 30:80-90

Cooper TF, Lai M, Ulstrup KE, Saunders SM, Flematti GR, Radford B, van Oppen MJH (2011a) Symbiodinium genotypic and environmental controls on lipids in reef building corals. PLoS One 6:e20434

Cooper TF, Ulstrup KE, Dandan SS, Heyward AJ, Kuhl M, Muirhead A, O'Leary RA, Ziersen BEF, Van Oppen MJH (2011b) Niche specialization of reef-building corals in the mesophotic zone: metabolic trade-offs between divergent Symbiodinium types. Proc R Soc Lond B Biol Sci 278:1840-1850

Cooper TF, Berkelmans R, Ulstrup KE, Weeks S, Radford B, Jones AM, Doyle J, Canto M, O'Leary RA, van Oppen MJH (2011c) Environmental factors controlling the distribution of Symbiodinium harboured by the coral Acroporamillepora on the Great Barrier Reef. PLoS One 6:e25536

DeSalvo MK, Sunagawa S, Fisher PL, Voolstra CR, Iglesias-Prieto R, Medina M (2010) Coral host transcriptomic states are correlated with Symbiodinium genotypes. Mol Ecol 19:1174-1186

DeWitt TJ, Sih A, Wilson DS (1998) Costs and limits of phenotypic plasticity. TREE 13:77-81

English S, Wilkinson C, Baker V (1997) Survey manual for tropical marine resources. Australian Institute of Marine Science, Townsville, Australia

Falkowski PG, Dubinsky Z (1981) Light-shade adaptation of Stylophorapistillata, a hermatypic coral from the Gulf of Eilat. Nature 289:172-174

Falkowski PG, Dubinsky Z, Muscatine L, Porter JW (1984) Light and the bioenergetics of a symbiotic coral. Bioscience 34:705-709

Ferrier-Pagès C, Witting J, Tambutté E, Sebens KP (2003) Effect of natural zooplankton feeding on the tissue and skeletal growth of the scleractinian coral Stylophorapistillata. Coral Reefs 22:229-240 
Ferrier-Pagès C, Allemand D, Gattuso JP, Jaubert J, Rassoulzadegan R (1998) Microheterotrophy in the zooxanthellate coral Stylophorapistillata: effects of light and ciliate density. Limnol Oceanogr 43:1639-1648

Frade PR, Bongaerts P, Winkelhagen AJS, Tonk L, Bak RPM (2008a) In situ photobiology of corals over large depth ranges: a multivariate analysis on the roles of environment, host, and algal symbiont. Limnol Oceanogr 53:2711-2723

Frade PR, De Jongh F, Vermeulen F, Van Bleijswijk J, Bak RPM (2008b) Variation in symbiont distribution between closely related coral species over large depth ranges. Mol Ecol 17:691-703

Franklin E, Stat M, Pochon X, Putnam H, Gates R (2012) GeoSymbio: a hybrid, cloud-based web application of global geospatial bioinformatics and ecoinformatics for Symbiodiniumhost symbioses. Mol Ecol Resour 12:369-373

Gates RD, Edmunds PJ (1999) The physiological mechanisms of acclimatization in tropical reef corals. Amer Zool 39:30-43

Grottoli AG, Rodrigues LJ, Palardy JE (2006) Heterotrophic plasticity and resilience in bleached corals. Nature 440:1186-1189

Hiller RG, Wrench PM, Gooley AP, Shoebridge G, Breton J (1993) The major intrinsic light-harvesting protein of Amphidinium: characterization and relation to other light-harvesting proteins. Photochem Photobiol 57:125-131

Hofmann E, Wrench PM, Sharples FP, Hiller RG, Welte W, Diederichs K (1996) Structural basis of light harvesting by carotenoids: peridinin-chlorophyll-protein from Amphidiniumcarterae. Science 272:1788-1791

Hoogenboom M, Rodolfo-Metalpa R, Ferrier-Pages C (2010) Covariation between autotrophy and heterotrophy in the Mediterranean coral Cladocoracaespitosa. J Exp Biol 213:2399-2409

Iglesias-Prieto R, Trench RK (1997) Acclimation and adaptation to irradiance in symbiotic dinoflagellates. II. Response of chlorophyll-protein complexes to different photon-flux densities. Mar Biol 130:23-33

Iglesias-Prieto R, Beltran VH, LaJeunesse TC, Reyes-Bonilla H, Thome PE (2004) Different algal symbionts explain the vertical distribution of dominant reef corals in the eastern Pacific. Proc R Soc Lond B Biol Sci 271:1757-1763

Jeffrey SW, Haxo FT (1968) Photosynthetic pigments of symbiotic dinoflagellates (zooxanthellae) from corals and clams. Biol Bull 135:149-165

Jeffrey SW, Humphrey GF (1975) New spectrophotometric equations for determining chlorophylls $\mathrm{a}, \mathrm{b}, \mathrm{c}_{1}$ and $\mathrm{c}_{2}$ in higher plants, algae and natural phytoplankton. Biochem Physiol Pflanz 167:191-194

Jones AM, Berkelmans R, van Oppen MJH, Mieog JC, Sinclair W (2008) A community change in the algal endosymbionts of a scleractinian coral following a natural bleaching event: field evidence of acclimatization. Proc R Soc Lond B Biol Sci 275:1359-1365

Kinzie RA, Jokiel PL, York R (1984) Effects of light of altered spectral composition on coral zooxanthellae associations and on zooxanthellae in vitro. Mar Biol 78:239-248

Kowalewska G, Szymczak M (2001) Influence of selected abiotic factors on the decomposition of chlorophylls. Oceanologia 43:315-328

Krämer WE, Schrameyer V, Hill R, Ralph PJ, Bischof K (2013) PSII activity and pigment dynamics of Symbiodinium in two IndoPacific corals exposed to short-term high-light stress. Mar Biol 160:563-577

LaJeunesse TC (2001) Investigating the biodiversity, ecology and phylogeny of endosymbionticdinoflagellates in the genus Symbiodinium using the ITS region: in search of a "species" level marker. J Phycol 37:866-880
LaJeunesse TC (2002) Diversity and community structure of symbiotic dinoflagellates from Caribbean coral reefs. Mar Biol 141:387-400

LaJeunesse TC, Trench RK (2000) Biogeography of two species of Symbiodinium (Freudenthal) inhabiting the intertidal sea anemone Anthopleuraelegantissima (Brandt). Biol Bull 199:126-134

LaJeunesse TC, Bonilla HR, Warner ME, Wills M, Schmidt GW, Fitt WK (2008) Specificity and stability in high latitude eastern Pacific coral-algal symbioses. Limnol Oceanogr 53:719-727

LaJeunesse TC, Smith R, Walther M, Pinzon J, Pettay DT, McGinley M, Aschaffenburg M, Medina-Rosas P, Cupul-Magana AL, Perez AL, Reyes-Bonilla H, Warner ME (2010) Host-symbiont recombination versus natural selection in the response of coraldinoflagellate symbioses to environmental disturbance. Proc R Soc Lond B Biol Sci 277:2925-2934

Lesser MP, Slattery M, Leichter JJ (2009) Ecology of mesophotic coral reefs. J Exp Mar Biol Ecol 375:1-8

Lesser MP, Slattery M, Stat M, Ojimi M, Gates RD, Grottoli A (2010) Photoacclimatization by the coral Montastraeacavernosa in the mesophotic zone: light, food, and genetics. Ecology 91:990-1003

Little AF, van Oppen MJH, Willis BL (2004) Flexibility in Algal Endosymbioses Shapes Growth in Reef Corals. Science 304:1492-1494

Lowry O, Rosebrough N, Farr A, Randall R (1951) Protein measurement with the Folin phenol reagent. J Biol Chem 193:265-275

McCloskey LR, Muscatine L (1984) Production and respiration in the Red Sea coral Stylophorapistillata as a function of depth. Proc R Soc Lond B Biol Sci 222:215-230

McGinley MP, Aschaffenburg MD, Pettay DT, Smith RT, LaJeunesse TC, Warner ME (2012) Symbiodinium spp. in colonies of eastern Pacific Pocillopora spp. are highly stable despite the prevalence of low-abundance background populations. Mar Ecol Prog Ser 462:1-7

Monismith SG (2007) Hydrodynamics of coral reefs. Annu Rev Fluid Mech 39:37-55

Muscatine L (1990) The role of symbiotic algae in carbon and energy flux in reef corals. In: Dubinsky Z (ed) Ecosystems of the world, coral reefs. Elsevier, Amsterdam, pp 75-87

Muscatine L, Porter JW, Kaplan IR (1989) Resource partitioning by reef corals as determined from stable isotope composition. Mar Biol 100:185-193

Nahon S, Richoux NB, Kolasinski J, Desmalades M, Ferrier-Pagès C, Lecellier G, Planes S, BerteauxLecellier V (2013) Spatial and temporal variations in stable carbon $\left(\delta^{13} \mathrm{C}\right)$ and nitrogen $\left(\delta^{15} \mathrm{~N}\right)$ isotopic composition of symbiotic scleractinian corals. PLoS One 8:e81247

Oku H, Yamashiro H, Onaga K, Sakai K, Iwasaki H (2003) Seasonal changes in the content and composition of lipids in the coral Goniastreaaspera. Coral Reefs 22:83-85

Padilla-Gamiño JL, Hanson KM, Stat M, Gates RD (2012) Phenotypic plasticity of the coral Poritesrus: acclimatization responses to a turbid environment. J Exp Mar Biol Ecol 434-435:71-80

Palardy JE, Grottoli AG, Matthews KA (2005) Effects of upwelling, depth, morphology and polyp size on feeding in three species of Panamanian corals. Mar Ecol Prog Ser 300:79-89

Palardy JE, Grottoli AG, Matthews KA (2006) Effect of naturally changing zooplankton concentrations on feeding rates of two coral species in the Eastern Pacific. J Exp Mar Biol Ecol 331:99-107

Palardy JE, Rodrigues LJ, Grottoli AG (2008) The importance of zooplankton to the daily metabolic carbon requirements of healthy and bleached corals at two depths. J Exp Mar Biol Ecol 367:180-188 
Papagiannakis E, van Stokkum IHM, Fey H, Büchel C, van Grondelle $R$ (2005) Spectroscopic characterization of the excitation energy transfer in the fucoxanthin-chlorophyll protein of diatoms. Photosynth Res 86:241-250

Patton JS, Abraham S, Benson AA (1977) Lipogenesis in the intact coral Pocilloporacapitata and its isolated zooxanthellae: evidence for a light-driven carbon cycle between symbiont and host. Mar Biol 44:235-247

Platt T, Gallegos CL, Harrison WG (1980) Photoinhibition of photosynthesis in natural assemblages of marine phytoplankton. J Mar Res 38:687-701

Pochon X, Putnam HM, Burki F, Gates RD (2012) Identifying and characterizing alternative molecular markers for the symbiotic and free-living dinoflagellategenus Symbiodinium. PLoS One 7:e29816

Ralph PJ, Gademann R, Larkum AWD, Schreiber U (1999) In situ underwater measurements of photosynthetic activity of coral zooxanthellae and other reef dwelling dinoflagelateendosymbionts. Mar Ecol Prog Ser 180:139-147

Roder C, Fillinger L, Jantzen C, Schmidt GM, Khokiattiwong S, Richter C (2010) Trophic response of corals to large amplitude internal waves. Mar Ecol Prog Ser 412:113-128

Roder C, Jantzen C, Schmidt GM, Kattner G, Phongsuwan N, Richter C (2011) Metabolic plasticity of the corals Poriteslutea and
Diploastreaheliopora exposed to large amplitude internal waves. Coral Reefs 30:57-69

Rodrigues LJ, Grottoli AG (2007) Energy reserves and metabolism as indicators of coral recovery from bleaching. Limnol Oceanogr 52:1874-1882

Swart PK, Saied A, Lamb K (2005) Temporal and spatial variation in the delta $\mathrm{N}-15$ and delta $\mathrm{C}-13$ of coral tissue and zooxanthellae in Montastraeafaveolata collected from the Florida reef tract. Limnol Oceanogr 50:1049-1058

Thornhill DJ, Xiang Y, Fitt WK, Santos SR (2009) Reef endemism, host specificity and temporal stability in populations of symbiotic dinoflagellates from two ecologically dominantCaribbean corals. PLoS One 4:e6262

Todd PA (2008) Morphological plasticity in scleractinian corals. Biol Rev 83:315-337

van Oppen MJH, Bongaerts P, Underwood JN, Peplow LM, Cooper TF (2011) The role of deep reefs in shallow reef recovery: an assessment of vertical connectivity in a brooding coral from west and east Australia. Mol Ecol 20:1647-1660

Veal CJ, Carmi M, Fine M, Hoegh-Guldberg O (2010) Increasing the accuracy of surface area estimation using single wax dipping of coral fragments. Coral Reefs 29:893-897

Wellington GM (1982) An experimental analysis of the effects of light and zooplankton on coral zonation. Oecologia 52:311-320 